study, necropsies were performed on 604 adult blacks from southern Africa and one of five grades of hepatic and splenic iron was assigned based on the Prussian blue reaction obtained when a piece of tissue was dipped in a mixture of potassium ferrocyanide and hydrochloric acid. ${ }^{11}$ Using logistic regression models, we found that iron overload was strongly associated with the findings of cirrhosis $(p<0.0001)$, HCC $(p=0.0002)$, and tuberculosis $(p<0.0001) .10$ Secondly, we reviewed all 320 diagnostic liver biopsy specimens processed at the University of Zimbabwe from 1992 to 1994 . HCC was present in $19 \%$ of the evaluable specimens, cirrhosis in $21 \%$, and high grades of iron in $19 \%$. We found significant associations between the presence of iron overload and the histological diagnoses of cirrhosis and HCC.

We do not completely share the pessimism of Drs Walker and Segal with regard to changing the method of preparation of traditional beer and to instituting a phlebotomy programme. The iron drums that are now used to prepare traditional beer replaced clay cooking pots around the turn of the century, but these clay utensils are still used in most rural communities to prepare food and other forms of beverages. It seems feasible to us to encourage the use of these clay pots for the preparation of traditional beer in place of the newer and more convenient, but probably more dangerous, iron drums. For the past two years our research team has conducted a rural based study of dietary iron overload. We have been struck by the overwhelming level of cooperation that we have been able to obtain through close and regular contact with the rural communities. Despite the need for venesection and a high awareness of the problem of HIV, it has been unusual for subjects to refuse to take part.

In summary, we believe the available data point to both HCC and dietary iron overload as major heath problems in rural Africa. There is a strong body of evidence to suggest an association between the two conditions. Major initiatives are needed to combat these diseases beginning in the communities where the people live.

INNOCENT TICHAONA GANGAIDZO Department of Medicine and the University of Zimbabwe School of Medicine, PO Box A178, Avondale,

Harare,

Zimbabwe

VICTOR ROLAND GORDEUK Department of Medicine,
George Washington University Medical Center,
Washington DC, $U S A$

1 Sackett DL, Hayes RB. Bias in analytic research. f Chron Dis 1979; 32: 51-63.

2 Kew MC. Hepatocellular carcinoma: epidemiology. In: Watters D, Kiire CF, eds. ogy. In: Watters D, Kiire CF, eds.
Gastroenterology in the tropics and subtropics. Gastroenterology in the tropics and
London: Macmillan, 1995: 184-6.

3 Cook GC. Hepatocellular carcinoma: one of the world's most common malignancies. Q F Med 1985; 57: 705-8.

4 Gordeuk VR, McLaren G, Samowitz W. Etiologies, consequences and treatment of iron overload. Crit Rev Lab Clin Med 1994; 31: 89-133.

5 Bothwell TH, Bradlow BA. Siderosis in the Bantu. A combined histopathological and chemical study. Arch Pathol 1960; 70: 279-92.

6 Bothwell TH, Isaacson C. Siderosis in the Bantu. A comparison of incidence in males and females. BMF 1962; i: 522-4.

7 Isaacson C, Seftel HC, Keeley KJ, Bothwell TH. Siderosis in the Bantu: the relationship between iron overload and cirrhosis. $\mathcal{F} \mathrm{Lab}$ between iron overload and
Clin Med 1962; 58: 845-53.

8 Bassett ML, Halliday JW, Powell LW. Identification of homozygous hemochromatosis subject by measurement of hepatic iron sis subject by measurement of
index. Hepatology 1986; 6: 24-9.
9 Friedman BM, Baynes RD, Bothwell $T H$ Gordeuk VR, MacFarlane BJ, Lamparelli RD, et al. Dietary iron overload in southern African et al. Dietary iron overload in southern
blacks. S Afr Med f 1990; 78: 301-5.

10 Gordeuk VR, MacPhail AP, McLaren CE Deichsel G, Bothwell TH. Associations of iron overload in Africa with hepatocellular carcinoma and tuberculosis: Strachan's 1929 thesis revisited. Blood 1996; 87: 3470-6.

11 Strachan AS. Haemosiderosis and haemochroma tosis in African natives with a comment on the aetiology of haemochromatosis. [MD thesis]. Glasgow: University of Glasgow, 1929.

\section{Analysis of biological variables in Crohn's disease}

EDITOR,-We wish to comment on the paper by Sahmoud et al (Gut 1995; 37: 811-8) where the authors suggested the following features: age, duration of disease, interval since previous relapse, and colonic involvement as powerful prognostic factors to predict relapse in quiescent Crohn's disease. We also followed up for 18 months 107 patients with Crohn's disease in clinical remission ${ }^{1}$ and we used laboratory tests enhanced by clinical characteristics for predicting relapse.

Interestingly, our results about clinical characteristics were, for some aspects, similar to those obtained by the French group. A Cox regression analysis indicated interval since previous relapse, previous surgery, location (ileum versus non-ileum), and occurrence of postsurgical clinical recurrence as predictors of relapse; however an intercorrelation was found among these characteristics and particularly between previous surgery and location (but simultaneous Cox regression indicated that surgery would be more predictive than location). Thus two groups of risk of relapse according to clinical characteristics were defined: (a) favourable group consisted of patients in clinical remission after last relapse for at least 24 months or patients with less than 24 months but who had undergone surgery without subsequent post surgical clinica recurrence; (b) unfavourable group consisted of patients in clinical remission for less than 24 months not included in the favourable group.

In the French study surgery was not identified as a prognostic factor; this could be explained because in that study quiescent disease induced by surgery seems to be excluded and ileal location (and for this reason also previous resection) is present in a small number of patients in comparison with colonic location. In our experience duration of illness was not a useful predictor of relapse; we did not study age of patients.

In the study by Sahmoud et al biological indicators such as albumin and erythrocyte sedimentation rate did not result in predicting the course of the disease; in contrast, in our experience, laboratory tests seem to be extremely useful for this aim. In a previous study $^{2}$ a prognostic index based on laboratory tests was proposed. In our last study ${ }^{1}$ the ability of this index to predict relapse was validated and a simplified application was proposed; patients with at least one of the laboratory tests changed ( $\alpha_{1}$ acid glycoprotein $>130 \mathrm{mg} / \mathrm{dl}$, or $\alpha_{2}$ globulin $>9.0 \mathrm{gm} / 1$ or erythrocyte sedimentation rate $>40 \mathrm{~mm} / \mathrm{h}$, or all three) presented within 18 months a relapse rate of $75 \%$ whereas in patients with normal tests it was $13 \%$. In our study nine among 18 false-negative (normal laboratory tests with subsequent relapse) were represented by patients with previous remission $<3$ months who had recently stopped corticosteroid treatment. Usually, however, values of laboratory tests are rapidly normalised by a period of corticosteroid treatment and it is shown ${ }^{34}$ that these tests, performed during or immediately after corticosteroids have poor ability in discriminating the clinical outcome. In our opinion the French investigators were unable to show a prognostic ability of sedimentation rate and albumin because at least 64 patients among 167 included were treated with corticosteroids at the entry of the study (placebo group of the trial about usefulness of prednisolone treatment in patients in clinical remission after prednisolone treatment for an acute attack).

We agree, however, with Sahmoud's conclusions about the necessity of identifying patients with different risks of relapse in quiescent Crohn's disease. In our study, at the end of 18 months of follow up, the predicted proportion of patients with relapse was $13 \%$ and $31 \%$ in the subgroup with normal laboratory tests and favourable and unfavourable clinic characteristics respectively, and $87 \%$ in patients with abnormal tests and unfavourable characteristics. Thus risk of relapse varies substantially among different subgroups of patients with clinical remission; prediction of this risk is helpful not only for a correct design of clinical trials, but also, in clinical practice, for timing subsequent clinical visits and for selecting groups of patients where preventive treatment could be justified.

C BRIGNOLA C BELLOLI MPIER P GIONCHETTI A BELLUZZI astroenterologia, Policlinico $S$ Orsola,, ,
Massarenti 9 Massarenti 9,
40138 Bologna, Italy

1 Brignola C, Iannone P, Belloli C, De Simone G, Bassein I, Gionchetti P, et al. Prediction of relapse in patients with Crohn's disease in remission: a simplified index using laboratory tests, enhanced by clinical characteristics. European fournal of Gastroenterology and Hepatology 1994; 6: 955-61.

2 Brignola C, Campieri M, Bazzocchi G, Farruggia P, Tragnone A, Lanfranchi GA. A laboratory $\mathrm{P}$, Tragnone A, Lanfranchi GA. A laboratory
index for predicting relapse in asymptomatic patients with Crohn's disease. Gastroenterology 1986; 91: 1490-4.

3 Landi B, N'Guyen Anh T, Cortot A, Soule JC, Rene E, Gendre JP, et al. Endoscopic monitoring of Crohn's Disease treatment: a prospective, randomized clinical trial. Gastroenterology 1992; 102: 1647-53.

4 Brignola C, De Simone G, Belloli C, Iannone P, Belluzzi A, Gionchetti $P$, et al. Steroid treatment in active Crohn's disease: a comparison between two regimens of different duration. Aliment Pharmacol Ther 1994; 8: 465-8.

\section{Reply}

EDITOR,-Thank you for referring the interesting comments of Brignola et al to us concerning our article. The Italian group has considerable experience in investigating the value of biological parameters in Crohn's disease and has published several research results in that field. One of their earliest publications ${ }^{1}$ suggested a prognostic index for predicting relapse in quiescent Crohn's disease patients using the baseline blood values of $\alpha_{1}$ glycoprotein, $\alpha_{2}$ globulin, and the erythrocyte sedimentation rate. This was based on data from 41 patients who had been in remission for at least six months. The same study suggested that the blood values of C-reactive protein and $\alpha_{1}$ antitrypsin were of borderline significance and the predictive value of some other biological variables were much less important, namely the haemoglobin concentration, the white blood cell count, serum iron, albumin, and $\gamma$ globulin blood values. 
The same study reported that the patients who relapsed during the follow up period had a significantly shorter pre-inclusion duration of remission than those who subsequently remained in remission. It should be noted that this laboratory index, besides the limited number of patients, was not adjusted for other patient and disease characteristics like the duration of remission, disease topography, age, etc.

More recently, the Italian group investigated the predictive value of 10 biological variables. ${ }^{2}$ For each variable various possible threshold values were tested with respect to predicting relapse at 18 months. To construct the prognostic index, they stated that 'all possible combinations of the most predictive laboratory test, dichotomised, were compared in terms of relapse prediction'. This methodology, although leading to nicely separated time to relapse curves, is based on the most discriminating combination of the most predictive variables. It suffers from the multiplicity of tests and the results are most probably an overfit of the data. Indeed, these biological variables would not provide such good results if applied to an independent data set. Also, no justification was provided for opting for this methodology instead of using a time to event analysis, for example, the Cox proportional hazards regression model. ${ }^{3}$ One also notices that the three variables that constituted their first model were also available in their second study but no attempt was made to validate the first prognostic model.

Finally, we do not think that the debate is closed with respect to the prognostic value of biological variables. Moreover, we are convinced that repeatedly collecting laboratory measures, for instance every three to six weeks during the course of the disease and using a repeated measures analysis technique, for example, Cox model with time dependent covariates, would be more suitable for investigating the prognostic importance of the different biological variables.

T SAHMOUD R SYLVESTER R MODIGLIANI J-Y MARY EORTC Data Center
Av E Mounier $83 / 11$ 1200 Brussels,

Belgium

1 Brignola C, Campieri M, Bazzocchi G, Farruggia P, Tragnone A, Lanfranchi GA. A laboratory , Tragnone A, Lanfranchi GA. A laboratory index for predicting relapse in asymptomatic 1986; 91: 1490-94.

2 Brignola C, Iannone P, Belloli C, De Simone G, Bassein L, Gionchetti P, et al. Prediction of relapse in patients with Crohn's disease in remission: a simplified index using laboratory tests, enhanced by clinical characteristics. European fournal of Gastroenterology and Hepatology 1994; 6: 955-61.

3 Cox DR. Regression models and life-tables. fournal of the Royal Statistical Society (B) 1972; 34: 187-202.

\section{BOOK REVIEWS}

Clinical Surgery International 20. Colorectal Cancer. Edited by N S Williams. (Pp 187; illustrated; £49.50.) Edinburgh: Churchill Livingstone, 1996. ISBN 044-305-133X.
The smaller one's hospital, the more committees there are - even though they are all made up of the same few stalwart wearing different hats. I am reminded of this phenomenon when studying the authorship of this book: permutations of roughly the same names and subjects have appeared in other multi-author volumes. But the CSI series almost always produces attractive fresh compilations, usually from productively opinionated people, and Norman Williams' team in this volume on colorectal cancer is no exception.

Whether we like it or not, surgeons will need increasingly to be able to tell their ras from their ... hMSH2. Placed boldly in pole position in the chapter list, Phil Quirke and Lynn Cawkwell have produced a very digestible compendium on the molecular genetics of colorectal cancer. Although it will inevitably date quickly, this is highly recommended reading for the worried surgeon - no p53, no comment.

The screening chapter - from Nottingham, where else - opens with a beautifully simple and lucent explanation of the importan parameters of screening - effectiveness and efficacy, etc. It also provides the most current review of the ever-maturing European FOBT trials, and a useful bibliography on all aspects of the field.

The comprehensive chapter on polyps reflects the burgeoning development of molecular genetics and the more discerning approach to recurring endoscopy in the adenoma bearer. The de rigueur 'Vogelgram' is there, of course; although this distorted eponym places highly appropriate credit where much is due, the basic drawing will always be a 'Morsogram'.

Chapters on staging often do no more than palely reflect the confusion and turgidity that can engulf this subject. However, Newland, Chapuis, and Dent have produced a coherent, historically balanced and very readable description of the evolution and utility of staging since Lockhart-Mummery and Dukes started it all in the late 1920s. The authors' preference for clinicopathological staging though not accepted by many pathologists and even some surgeons, is well and persuasively defended.

A triad of chapters on surgical technique opens with one on sphincter saving from the editor, full of the sort of personal touches and comments that made Goligher so enjoyable. Next, transanal endoscopic microsurgery is described in detail by its originator, Gerhard Buess. The comparative infrequency of suitable cases in any one hospital is a problem with this approach. As Buess highlights, this is a technique for a few major centres; I suspec that if enough NHS Trusts were persuaded by enthusiastic specialists to buy the kit, there would be a considerable danger of overapplication - and hence what a venerated former chief once called 'a triumph of technique over common sense'. Surely we must restric this approach to a very few UK centres taking widespread referrals to allow authoritative assessment.

This led on naturally into the chapter covering laparoscopic colorectal cancer surgery. Steven Wexner can always be relied on to take a responsibly hesitant position in this difficult debate, and he has done so again here. However, I disagree with him that we may have a clear view of the efficacy of this approach in five years. The burden of proo within trials must be to show that the nove procedure - laparoscopic resection - is no sufficiently inferior in cancer outcome to standard treatment - open resection - as to be unacceptable (whatever its other merits), an unusual aspiration for a new treatment. To show equivalence, or anything acceptably close to it, would require the very unlikely randomisation of large numbers of patients. So more power to the elbows of Wexner and his colleagues as they try to prevent the sort of premature small town stampede that heralded the birth of 'lap chole'.

David Rothenberger's chapter on aspects of obstruction and perforation catches well the less hectic and more diverse approach to treatment these days - a far cry from Wangensteen's 1929 warning at the beginning of the chapter that: 'Colic obstruction... demands immediate surgical decompression (by transverse colostomy)'.

Widespread acceptance of adjuvant therapy occurred more rapidly in the United States than in the United Kingdom. Blanket delivery of chemotherapy, at least in stage C disease, and the ditching of important trials with 'no treatment' arms, ran worryingly ahead of the data a few years ago. A comprehensive piece on radiotherapy from Roger James, followed by a briefer contribution on chemotherapy and immunotherapy from David Kerr, provide a more realistic balance. David Kerr's final assertion - that '... a dialectical syncretism between scientists and clinicians beckons' left this clinician and his Apple Mac thesaurus bemused rather than beckoned. The Shorter Oxford indicated that syncretism is 'an attempted reconciliation of diverse or opposite tenets'. Perhaps, Professor.

This enjoyable and densely packed book ends with useful chapters on the old chestnut of follow up and the slightly newer one of aggressive management of liver metastases from Lars Pahlman and Glenn Steele respectively. This book is not cheap at $£ 49$.50, but I advise the investment nevertheless.

JOHN NORTHOVER

CT sonography of the acute abdomen. 2nd ed. By R Brooke Jeffrey, Philip W Ralls, with contributing author Faye $\mathrm{C}$ Laing. ( $\mathrm{Pp}$ 377; illustrated; £103.50.) Philadelphia: Lippincott-Raven, 1995. ISBN 0-78170287-9.

This is an excellent text book covering a wide range of conditions, which a large hospital would expect to see in patients that present with an acute abdomen disorder. It is well laid out along fairly predictable lines with chapters on the liver, biliary system, spleen, pancreas, kidney/adrenal, gastrointestinal tract, pelvis, and retroperitoneum. At the start there is philosophical overview about the investigation of the acute abdomen and an explanation of the techniques used

Perhaps the illustrations are the most impressive feature. Certainly one could glean quite a lot about the contents just by going through them all. For reasons of economy the excellent colour Doppler images are kept separate in a centrefold of all the colour prints. This causes minor difficulties when the colour image is not at hand at the relevant point in the text. Just occasionally the legend is not quite appropriate (viz 5.71, 6.9, 7.53) and a few of the cases are repeated in differen chapters, but on the whole the standard of editing is very high.

The text is well referenced throughout with a reasonable mix of the original CT/US references of the early 1980 s as well as the modern 